\title{
The Mechanism of Alkane Selective Oxidation by the M1 Phase of Mo-V-Nb-Te Mixed Metal Oxides: Suggestions for Improved Catalysts
}

\author{
Mu-Jeng Cheng, and William A. Goddard III* \\ Materials and Process Simulation Center (139-74), \\ California Institute of Technology, Pasadena CA 91125 USA, \\ Submitted to Topics of Catalysis Irsee VII special issue \\ *Email: wag@wag.caltech.edu
}

\begin{abstract}
.
We report here first principles predictions (density functional theory with periodic boundary conditions) of the structures, mechanisms, and activation barriers for the catalytic activation and functionalization of propane by the M1 phase of the Mitsubishi-BP America generation of Mo-VNb-Te-O mixed metal oxide (MMO) catalysts.

Our calculations show that the Reduction-coupled Oxo Activation (ROA) principle, which we reported at Irsee VI to play the critical role for the selective oxidation of $n$-butane to maleic anhydride by vanadium phosphorous oxide (VPO), also plays the critical role for the MMO activation of propane, as speculated during Irsee VI. However for MMO, this ROA principle involves $\mathrm{Te}=\mathrm{O}$ and $\mathrm{V}$ rather than $\mathrm{P}=\mathrm{O}$ and $\mathrm{V}$.

The ability of the $\mathrm{Te}=\mathrm{O}$ bond to activate the propane $\mathrm{CH}$ bond depends sensitively upon the number of $\mathrm{V}$ atoms that are coupled through a bridging $\mathrm{O}$ to the $\mathrm{Te}=\mathrm{O}$ center. Based on this ROA mechanism, we suggest synthetic procedures aimed at developing a single phase MMO catalyst with dramatically improved selectivity for ammoxidation. We also suggest a modified single phase composition suitable for simultaneous oxidative dehydrogenation $(\mathrm{ODH})$ of ethane and propane to ethene and propene, respectively, which is becoming more important with the increase in petroleum fracking. Moreover, we also suggest some organometallic molecules that activate alkane $\mathrm{CH}$ bonds through the ROA principle.
\end{abstract}

\section{Introduction}

Alkanes are the major components of natural gas and petroleum; however, there are few practical processes that can selectively oxidize them into more valuable products such as alkenes or alcohols. The development of improved catalytic processes to convert alkanes to more valuable functionalized hydrocarbons would produce enormous economic benefits. The key to achieving this goal is to develop a catalyst with high selectivity, high activity, and high conversion. We will focus here on the selective oxidation or ammoxidation of propane to products such as acrolein and acrylonitrile (AN) by the M1 phase of Mo-V-Nb-Te-O mixed metal oxide (MMO) generation of catalysts, pioneered by Mitsubishi and BP America in 1995.

In section 2, we summarize the computational methods; in section 3, we review the critical points from our previous work on vanadium phosphorous oxide (VPO) and the discovery of the Reduction-coupled Oxo Activation (ROA) mechanism, responsible for activating the strong $\mathrm{CH}$ bonds of $n$-butane.[1-3] In section 4, we use quantum mechanics (QM) to examine the activation of propane by the M1 phase, where we use the improved experimental analysis of the partial 
occupations of the various sites.[4] Here we examine how the activation energy for propane depends on the specific distributions over the sites.[5] We conclude that critical to activation of propane is to have $\mathrm{Te}=\mathrm{O}$ at both $\mathrm{S} 12$ sites of the S12-S2-S12 triad site coupled with two or more $\mathrm{V}$ at S2, S4, and S7 sites. Also in section 4 we discuss how to use the results of these QM studies and the understanding of the ROA mechanism to design improved catalysts. In section 5 we review our design of the organometallic catalysts based on the ROA principle for oxidative dehydrogenation (ODH) of alkanes.[6]

\section{Computational details}

To determine the mechanism of these catalytic processes we use the density functional theory (DFT) form of QM with periodic surface cells. Here we determine how the reactivity for activating propane depends on the distributions of atoms over the various crystal sites. We use this to discover the catalytic reaction center. Perdew-Burke-Ernzerhof (PBE) functional[7] and GBRV ultrasoft pseudopotentials[8] with planewave basis sets (the cutoff energy was 40 Ry for wavefunctions and 160 Ry for charge density), as implemented in the QUANTUM-ESPRESSO package,[9] were used for all calculations. Electron smearing was employed using Gaussiansmearing with a width of $0.01 \mathrm{Ry}$, and then energies were extrapolated to $k_{B} \mathrm{~T}=0$. Spin-polarized wavefunctions were used for all calculations. For all surface calculations, only the gamma point was sampled because of the large cell used. At least $15 \AA$ vacuum spacing between adjacent images was used to prevent interactions between periodic replicas along the $z$-direction.

We focus here on the M1 phase, since the experiments indicate that only this phase can activate propane and that it leads to the initial production of propene.[10, 11] Assuming that the S13 site is empty and that the S12 sites are fully occupied, one single unit cell of M1 still has 160 atoms.[4] Therefore it is computationally impractical to use a surface model containing more than one layer. Fortunately, the experiments show that M1 has a distinct layered structure along the $c$ axis, with two adjacent layers connected only through coordinate bonds, $\mathrm{M}=\mathrm{O}-\mathrm{-}-\mathrm{M}=\mathrm{O}$ motifs ( $\mathrm{M}$ = Mo, $\mathrm{V}, \mathrm{Nb}$ and Te).[4] This makes the preparation of the one-layer surface model from the crystal structure unambiguous by breaking only the longer $\mathrm{M}---\mathrm{O}$ coordinate bond, while keeping shorter $\mathrm{M}=\mathrm{O}$ intact. The surface is arranged in such a way that oxygen of the $\mathrm{M}=\mathrm{O}$ bonds in sites $\mathrm{S} 2, \mathrm{~S} 5, \mathrm{~S} 6, \mathrm{~S} 8, \mathrm{~S} 10$, and $\mathrm{S} 11$ point toward the same direction as that of $\mathrm{Te}=\mathrm{O}$ at $\mathrm{S} 12$, while those of $\mathrm{M}=\mathrm{O}$ in sites $\mathrm{S} 1, \mathrm{~S} 3, \mathrm{~S} 4, \mathrm{~S} 7$, and S9 point toward the opposite direction.

Figure 1. Model Structure used in the QM calculations on Mo-V-Nb-Te-O, with no V sites. Note that we assume that Te is at both S12 sites, although this site is only 71.1\% occupied by Te (colored by blown), and we assume S13 is empty although experimentally it is $14.6 \%$ occupied.[4] Besides those sites, S9 is occupied by $\mathrm{Nb}$ (colored by green), while all other sites are occupied by Mo (colored by pink). Polyhedrons with violet labels mean that their oxo's point down, whereas those with white labels mean that they oxo's point up. 


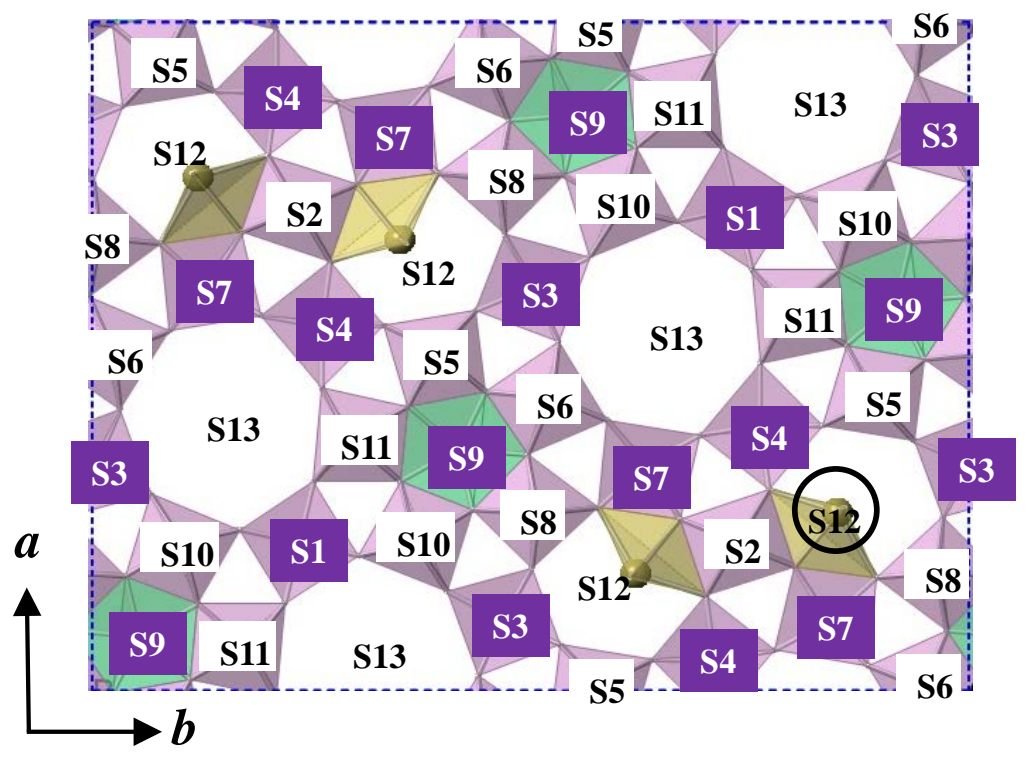

\section{The Reaction Mechanism for Butane to Maleic anhydride on VPO}

\subsection{Electronic Structures of ( $\mathrm{VO})_{2} \mathrm{P}_{2} \mathrm{O}_{7}$}

Since (VO) ${ }_{2} \mathrm{P}_{2} \mathrm{O}_{7}$ (VOPO) is the major component of the VPO catalyst,[12] we studied the high temperature, high symmetry structure of VOPO (Figure 2). The nature of chemical bonds in VOPO was explored by investigating the variations in V-O bond lengths as a functional of strain along the $a$ axis through compressing and stretching the cell parameter $a$ by 3 and 5\%, respectively.[1]

Figure 2. Polyhedral views of the crystal structure of the high-symmetry form of VOPO.[13] The blue and yellow polyhedrons represent the $\mathrm{V}_{2} \mathrm{O}_{8}$ and $\mathrm{P}_{2} \mathrm{O}_{7}$ motifs, respectively. 
(a) Top view

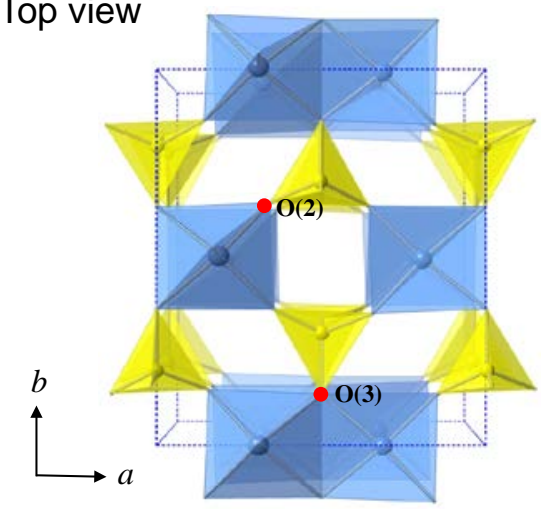

(b) Side view

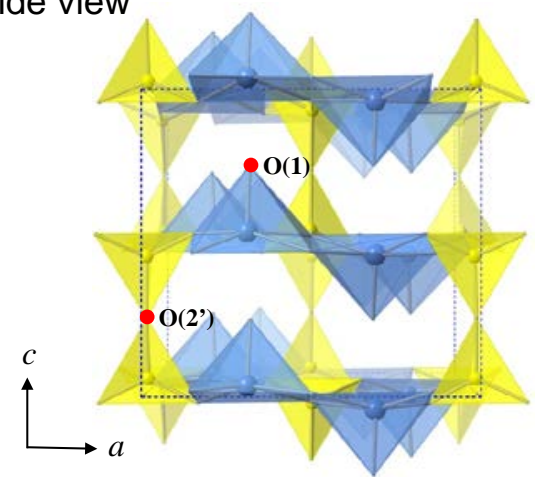

We found that $\mathrm{R}(\mathrm{V}-\mathrm{O}(3))$ increases from 2.04 and $2.03 \AA$ to 2.19 and $2.16 \AA$ (6.9 \% variation), as the $a$ lattice parameter increases from $97 \%$ to $105 \%$ (Scheme 1(a)). Further expanding $a$ to 110 \% increases the $\mathrm{V}-\mathrm{O}(3)$ bond lengths to 2.43 and $2.23 \AA$. The $\mathrm{V}_{2} \mathrm{O}_{8}$ cluster distorts such that one $\mathrm{P}=\mathrm{O}(3)$ group makes a donor-acceptor bond to one $\mathrm{V}$, while the other $\mathrm{P}=\mathrm{O}(3)$ group makes a donoracceptor bond to the other $\mathrm{V}$. In contrast, $\mathrm{V}-\mathrm{O}(2)$ increases only from 1.92 to $1.98 \AA$ (a $3.0 \%$ change), as the a lattice parameter is changed from $97 \%$ to $105 \%$. Further expanding $a$ to $110 \%$ leads to a $\mathrm{V}-\mathrm{O}(2)$ bond length of $1.98 \AA$, the same as at $5 \%$ expansion. Based on these asymmetric variations of the $\mathrm{V}-\mathrm{O}$ bond lengths, we concluded that $\mathrm{V}-\mathrm{O}(2)$ is a rigid covalent single bond while $\mathrm{V}-\mathrm{O}(3)$ is a fragile dative bond (Scheme 1(b)).[1] This valence bond description plays an important role in understanding the catalysis.

(a)

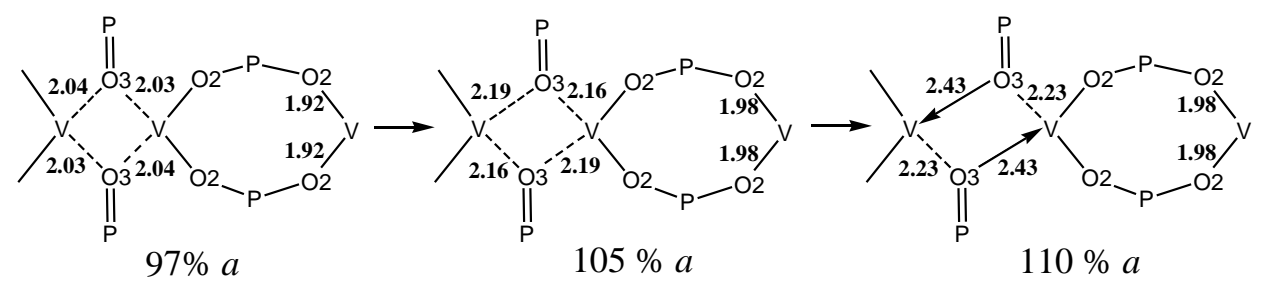

(b)

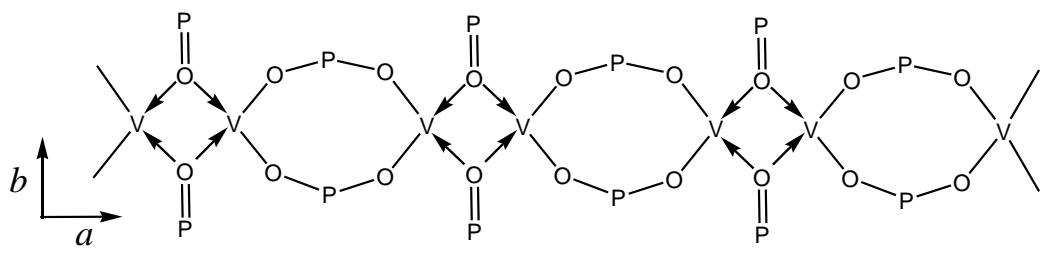


Scheme 1. (a) Variations in the $\mathrm{V}-\mathrm{O}(2)$ and $\mathrm{V}-\mathrm{O}(3)$ bond lengths for various a cell parameters; (b) Valence bond description of the bonding along the $a$ direction, where dative bonds are represented by arrows.

\subsection{Reactivity of VOPO toward $\boldsymbol{n}$-butane C-H Activation}

With this understanding of the nature of chemical bonds, we next studied the reaction mechanism for the selective oxidation of $n$-butane to maleic anhydride.[2, 3] We first focused on identifying the reaction center responsible for activating the methylene $\mathrm{C}-\mathrm{H}$ bond of $n$-butane. Only the [001] surface of VOPO is considered, since experiments have suggested that it plays an important role in the catalysis.[14]

We expect that cleavage of the alkane $\mathrm{C}-\mathrm{H}$ bond by a surface oxygen atom to form a new $\mathrm{OH}$ bond involves a linear $\mathrm{C}--\mathrm{H}--\mathrm{O}$ reaction pathway, along which an $\mathrm{O}-\mathrm{H}$ bond is formed while the $\mathrm{C}-\mathrm{H}$ bond is cleaved. Here the minimum energy barrier is estimated to be $\mathrm{E}_{\mathrm{a}, \mathrm{min}}=\mathrm{D}_{\mathrm{C}-\mathrm{H}}-\mathrm{D}_{\mathrm{O}-\mathrm{H}}$. Since $\mathrm{D}_{\mathrm{C}-\mathrm{H}}=98.3 \mathrm{kcal} / \mathrm{mol}$ for $n$-butane, then to have $\mathrm{E}_{\mathrm{a} \text {,min }} \sim 15.0 \mathrm{kcal} / \mathrm{mol}$ requires that $\mathrm{D}_{\mathrm{O}-\mathrm{H}}>$ $83.3 \mathrm{kcal} / \mathrm{mol}$ for the new $\mathrm{OH}$ bond. Therefore, we need only to examine the bond energy, $\mathrm{D}_{\mathrm{O}-\mathrm{H}}$, for various sites to estimate the reactivity of the surface. After identifying the site whose $\mathrm{D}_{\mathrm{O}-\mathrm{H}}$ is sufficiently strong, we can proceed to calculate the transition state, which is generally $\sim 5 \mathrm{kcal} / \mathrm{mol}$ higher than $\mathrm{E}_{\mathrm{a} \text {,min. }}$.

We calculated $\mathrm{D}_{\mathrm{O}-\mathrm{H}}$ 's for all three types of oxygen atoms $(\mathrm{O}(1), \mathrm{O}(2)$, and $\mathrm{O}(3))$ on the surface of VOPO[001], and find none of them ( $\mathrm{D}_{\mathrm{O}-\mathrm{H}}$ 's $<59 \mathrm{kcal} / \mathrm{mol}$ ) is reactive enough to provide a $\mathrm{E}_{\mathrm{a} \text {,min }}$ $\sim 15.0 \mathrm{kcal} / \mathrm{mol}$. It has been speculated that that gaseous $\mathrm{O}_{2}$ might adsorb on the VOPO surface in a molecular or dissociative fashion, oxidizing $\mathrm{V}^{+4}$ to $\mathrm{V}^{+5}$ and forming very reactive oxygen species in the form of $\mathrm{O}^{-}, \mathrm{O}_{2}{ }^{-1}$, or $\mathrm{O}_{2}{ }^{-2}$, which may be responsible for the initial C-H cleavage.[1517] Therefore, we also examined the reactivity of these adsorbed oxygen species, and find that they are still not reactive enough ( $\mathrm{D}_{\mathrm{O}-\mathrm{H}}$ 's $<71 \mathrm{kcal} / \mathrm{mol}$ ). Based those results, we concluded that both surface oxygen and adsorbed oxygen species are not the active site for initial $\boldsymbol{n}$-butane C-H activation.

\subsection{Reactivity of $\mathrm{VOPO}_{4}$ toward $n$-Butane C-H Activation}

Experiments have shown that during the transformation of $\mathrm{VOHPO}_{4}$ to $\mathrm{VOPO}$ during the selective oxidation of $n$-butane to MA by VOPO small domains of $\alpha_{\mathrm{I}^{-}}, \alpha_{\mathrm{II}}-, \beta-, \delta_{-}$, and $\gamma$-phases of $\mathrm{VOPO}_{4}$ are formed on the surface.[18, 19] This opens the possibility that the $\mathrm{V}^{+5}$ sites responsible for alkane and furan activation may come from the small amounts of $\mathrm{VOPO}_{4}$.[20]

As a result, we considered three phases of $\mathrm{VOPO}_{4}$ : $\alpha_{\mathrm{I}},[21] \alpha \mathrm{II},[22]$ and the proposed $\mathrm{X}_{1}$ phase.[23, 24] We found that

- On the $\alpha_{\mathrm{I}}$ surface: $\mathrm{D}_{\mathrm{O}-\mathrm{H}}=49.2 \mathrm{kcal} / \mathrm{mol}$ for $\mathrm{O}(1)$ and $48.5 \mathrm{kcal} / \mathrm{mol}$ for $\mathrm{O}(2)$, leading to

$\mathrm{E}_{\mathrm{a}, \min }=49.1$ and $49.8 \mathrm{kcal} / \mathrm{mol}$, respectively, far too high to be the active catalyst

- On the $\alpha_{\text {II }}$ surface: $D_{\mathrm{O}-\mathrm{H}}=52.1 \mathrm{kcal} / \mathrm{mol}$ for $\mathrm{O}(1)$ and $45.2 \mathrm{kcal} / \mathrm{mol} \mathrm{O}(2)$, leading to $\mathrm{E}_{\mathrm{a}, \mathrm{min}}$ $=36.2$ and $43.1 \mathrm{kcal} / \mathrm{mol}$, respectively, far too high to be the active catalyst.

Thus these surface oxygen atoms cannot be responsible for activating the $n$-butane C-H bonds.

Next, we investigated the C-H activation ability of oxygen on the surface of $\mathrm{X}_{1}-\mathrm{VOPO}_{4}$. 
- On the $\mathrm{X}_{1}-\mathrm{VOPO}_{4}$ surface: $\mathrm{D}_{\mathrm{O}-\mathrm{H}}=62.8$ for $\mathrm{O}(2)$ and $\mathrm{D}_{\mathrm{O}-\mathrm{H}}=51.6 \mathrm{kcal} / \mathrm{mol}$ for $\mathrm{O}(3)$.[3] This leads to $\mathrm{E}_{\mathrm{a} \text {,min }}=35.5 \mathrm{kcal} / \mathrm{mol}$, better than those for the $\alpha_{\mathrm{I}^{-}}$and $\alpha_{\mathrm{II}^{-}}-\mathrm{VOPO}_{4}$ surfaces, but still not reactive enough to lead to explain the experiments.[15]

This leaves us in the untenable position that no $\mathrm{V}$ site on any of the reduced or oxidized surfaces of VPO can explain the observed activation of $\boldsymbol{n}$-butane.

The clue providing the solution to this enigma is that our attempt to obtain $\mathrm{D}_{\mathrm{o}-\mathrm{H}}$ for $\mathrm{O}(1)$ on the $\mathrm{X}_{1}-\mathrm{VOPO}_{4}$ surface failed, because during the structural optimization, the hydrogen that we initially placed to bind with $\mathrm{O}(1)=\mathrm{V}$ migrated and bound instead to the oxygen of $\mathrm{O}(1)=\mathrm{P}$ ! Most surprising is that binding the $\mathrm{H}$ to the $\mathbf{P}=\mathbf{O}$ bond leads to a Do-H $=\mathbf{8 4 . 3} \mathbf{~ k c a l} / \mathbf{m o l}$, by far the largest for all other sites of all six phases of the VPO systems. The reaction at the $\mathbf{P}=\mathbf{O}$ site of the $X_{1}$ phase would lead to $E_{a, \min }=14.0 \mathrm{kcal} / \mathrm{mol}$, quite compatible with the observed activation of $\boldsymbol{n}$-butane.

In order to understand this most remarkable chemistry, we analyzed the spin density, and found that after hydrogen transfers the proton to $\mathrm{O}(1)=\mathrm{P}$ to form the $\mathrm{P}-\mathrm{OH}$ bond, the $\mathrm{P}-\mathrm{O}$ bond to a $\mathrm{V}$ changes to a $\mathrm{P}=\mathrm{O}$ double bond, and the electron from the original $\mathrm{CH}$ bond is delocalized over two nearby vanadium atoms ( $0.61 \mathrm{e}^{-}$and $0.45 \mathrm{e}^{-}$, Löwdin charge).[3] This means that the electron and proton of the transferred hydrogen atom are separated to be hosted by two very different motifs: $\mathrm{O}=\mathrm{P}$ for the proton and $\mathrm{V}$ for the electron, which are separated by at least $4 \AA$ in the $\mathrm{X}_{1}-\mathrm{VOPO}_{4}$ structure. This is a unique new mechanism for activating $\mathrm{C}-\mathrm{H}$ bonds, never previously suggested. Critical to this mechanism is that the oxo of $\mathrm{O}=\mathrm{P}$ is coupled to a transition metal that is prone to reduction. We refer to this as the "Reduction-Coupled Oxo Activation (ROA)" mechanism.[2, 6] As discussed below, we find that exactly this same ROA mechanism plays an essential role in the chemistry of the M1 phase of the Mo-V-Nb-Te-O MMO catalysts and we suggest it may play a similar role in other metal oxide catalysts.

\section{The Reaction Mechanism for propane to Propene on the M1 phase of the Mo-V-Nb-Te-O MMO catalysts}

The Mo-V-Nb-Te-O MMO generation of propane activation catalysts discovered by Mitsubishi Chemical Company and by BP-America in 1990s, offer a tremendous advantage over the BiMoOx based propene ammoxidation catalysts developed and optimized by SOHIO over the 1960's to 1980's.[11] Propane is a much less expensive feedstock, offering great economic and energy consumption advantages for producing the industrially important acrylonitrile. This catalytic process has great potential to achieve commercial application, if its selectivity can be improved significantly from the current value of $61.8 \%$.[11]

A great deal of progress has been made on improving the selectivity, activity, and conversion of the Mo-V-Nb-Te-O MMO ammoxidation catalysts. It is generally believed that there are two important phases:[10]

- The M1 phase is believed to be very effective at converting propane to propene (ODH), but it leads to low selectivity for producing acrylonitrile (AN) probably because of low selectivity for functionalizing propene to AN on this very active surface.[10, 25]

- The M2 phase is very selective in activating and functionalizing propene to AN, but it cannot activate propane.[25] 
We discussed in some detail the M2 catalyst at Irsee IV, where we used the ReaxFF reactive force field to resolve the partial occupations in the Rietveld crystal strucures to form a $2 \times 3 \times 4$ supercell that resolved the structure into whole atoms.[26] We then built models of the stable surfaces and examined the activation of propene. We found that the surface $\mathrm{V}=\mathrm{O}$ and $\mathrm{Mo}=\mathrm{O}$ species could not activate propene, whereas most surface $\mathrm{Te}=\mathrm{O}$ sites could. This special activity is attributed to the Te-O-Te-O chains observed in the Rietveld analysis. Here we found the Te to be in the +4 oxidation state, with a preference for $\mathrm{T}=\mathrm{O}$ bonds along the chain (z-direction) and two Te-O bonds in the xy plane that bridged to $\mathrm{V}$ or Mo centers. In these ReaxFF calculations we did not analyze the changes in charges or bond lengths to the coupled, Mo or V sites. The ROA mechanism might well play a role in this process.

Next we focus on the activation of propane and the conversion to propene for the M1 phase. Then we discuss the origin of the low selectivity and propose a modified composition that should improve selectivity.

\subsection{The mechanism for activating the propane $\mathrm{CH}$ bond in the $\mathrm{M1}$ phase of the Mo-V-Nb-Te- O Mixed Metal Oxides catalysts}

Studying the M1 phase of Mo-V-Nb-Te mixed metal oxides using quantum mechanics is quite challenging for at least two reasons. First, the Rietveld unit cell of the M1 phase contains 160 atoms in just the top layer, including four Nb, four Te, $36 \mathrm{Mo}$ (or V), and 116 oxygen, making it computationally demanding.[5] Secondly, eight of the 13 distinct sites exhibit partial occupation by either molybdenum or vanadium, while two other sites are only partially occupied, making it difficult to design an unambiguous surface model.[4] To do this we should enlarge the unit cell sufficiently that every site can be occupied by whole atoms. Indeed we did this for the M2 phase using the ReaxFF reactive force field to find the optimum configuration, which required a $2 \times 3 \times 4$ supercell.[26] A similar supercell for M1 would require 3840 atoms, far too large for QM. Thus previous computational studies have focused on developing algorithms to determine the exact locations of molybdenum and vanadium atoms rather than studying the reaction mechanism.[27, 28]

In preparation for this talk, we completed a full density functional theory study on the M1 phase, with a focus on determining how the Mo/V partial occupations would affect the reactivity of the M1 phase to propane $\mathrm{C}-\mathrm{H}$ activation.[5] In addition, we studied the ODH mechanism of propane to propene.

\subsubsection{Activating the propane $\mathrm{CH}$ bond with $\mathrm{OV}$}

We started with a surface model containing no vanadium atom (the $0 \mathrm{~V}$ case, Figure 1), and calculated the $\mathrm{D}_{\mathrm{O}-\mathrm{H}}$ for each surface oxygen to identify the most reactive site for initial C-H activation. Since the $\mathrm{D}_{\mathrm{C}-\mathrm{H}}$ for propane methylene $\mathrm{C}-\mathrm{H}$ bond is $100.7 \mathrm{kcal} / \mathrm{mol}$ ),[5] we estimated $\mathrm{E}_{\mathrm{a} \text {,min }}=100.7-\mathrm{D}_{\mathrm{O}-\mathrm{H}}$. The calculated $\mathrm{D}_{\mathrm{O}-\mathrm{H}}$ 's were listed below (all energies in $\mathrm{kcal} / \mathrm{mol}$ ):

- $\mathrm{Te}=\mathrm{O}, \mathrm{S} 12: \mathrm{D}_{\mathrm{O}-\mathrm{H}}=66.4 \rightarrow \mathrm{E}_{\mathrm{a}, \min }=34.3$

- $\mathrm{Nb}=\mathrm{O}$, S9: $\mathrm{D}_{\mathrm{O}-\mathrm{H}}=46.4 \rightarrow \mathrm{E}_{\mathrm{a}, \min }=54.3$

- $\mathrm{Mo}=\mathrm{O}, \mathrm{S} 11: \mathrm{D}_{\mathrm{O}-\mathrm{H}}=40.2$

- $\mathrm{Mo}=\mathrm{O}, \mathrm{S} 2: \mathrm{D}_{\mathrm{O}-\mathrm{H}}=35.5$

We also investigated the possible role of bridging oxygen sites, where we find 
- $\operatorname{Mo}(\mathrm{S} 4)-\mathrm{O}-\mathrm{Mo}(\mathrm{S} 7) .51 .1 \rightarrow \mathrm{E}_{\mathrm{a}, \min }=49.6$

- $\mathrm{Mo}(\mathrm{S} 2)-\mathrm{O}-\mathrm{Mo}(\mathrm{S} 4)$ : $\mathrm{D} \mathrm{O}-\mathrm{H}=48.8$

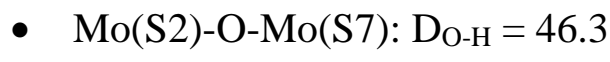

Thus the most reactive site is $\mathrm{O}=\mathrm{Te}$ at $\mathrm{S} 12$ with $\mathrm{E}_{\mathrm{a}, \mathrm{min}}=34.3 \mathrm{kcal} / \mathrm{mol}$. Just as for the VPO system, we found that during the reaction the proton binds to the $\mathrm{O}=\mathrm{Te}$ to form $\mathrm{Te}-\mathrm{OH}$, while the bonds on the Te rearrange to point the $\mathrm{Te}=\mathrm{O}$ at a nearby $\mathrm{Mo}$, and the electron is transferred to two nearby Mo atoms. This shows clearly that activating the propane $\mathrm{C}-\mathrm{H}$ bonds by $\mathrm{Te}=\mathbf{O}$ proceeds through the ROA mechanism. We find that the $2^{\text {nd }}$ most active site is a bridging site, which is more active than the $\mathrm{Mo}=\mathrm{O}$ and $\mathrm{Nb}=\mathrm{O}$ sites, indicating that $\mathrm{Mo}=\mathrm{O}$ bonds are not effective in activating propane.

\subsubsection{Activating the propane $\mathrm{CH}$ bond with $\mathbf{1 V}$}

Next we considered the $1 \mathrm{~V}$ case (Figure 3 ). Since the experiments show the most probable $\mathrm{V}$ site to be S2 at $58.0 \%,[4]$ one Mo at S2 is replaced by V. The important calculated $\mathrm{D}_{\mathrm{O}-\mathrm{H}}{ }^{\text {'s }}$ $(\mathrm{kcal} / \mathrm{mol})$ are listed below.

- $\mathrm{V}=\mathrm{O}$ at $\mathrm{S} 2: \mathrm{D}_{\mathrm{O}-\mathrm{H}}=55.0 \rightarrow \mathrm{E}_{\mathrm{a}, \mathrm{min}}=45.7$. This $\mathrm{V}=\mathrm{O}$ is much more active than the $\mathrm{Mo}=\mathrm{O}$ and $\mathrm{Nb}=\mathrm{O}$ bonds, but it still does not compete with $\mathrm{Te}=\mathrm{O}$.

- $\mathrm{Te}=\mathrm{O}$ at S12: $\mathrm{D}_{\mathrm{o}-\mathrm{H}}=66.4 \rightarrow \mathrm{E}_{\mathrm{a}, \min }=34.3$. Here again we find that forming the TeO-H bond, leads to no change of the SD of Te, while the SD on Mo at the adjacent S5 site increases from 0.01 to 0.55 e-, the signature of the ROA mechanism. Moreover, we find that the spin density of $\mathrm{V}$ at $\mathrm{S} 2$ increases slightly from 0.92 to 1.01, indicating that this vanadium remains in the +4 oxidation state.

Since previous speculations[29] assumed that the propane activating sites are the partially occupied S4 and/or S7 sites, we examined another configuration for the $1 \mathrm{~V}$ case in which Mo in $\mathrm{S} 7$ is replaced by $\mathrm{V}$. This leads to

- $\mathrm{V}=\mathrm{O}$ (S7): activation by V=O at S7: Do-H $=48.5 \mathrm{kcal} / \mathrm{mol} \rightarrow \mathrm{E}_{\mathrm{a}, \min }=52.2 \mathrm{kcal} / \mathrm{mol}$.

Thus a $\mathrm{V}=\mathrm{O}$ at $\mathrm{S} 2$ is the most active $\mathrm{V}=\mathrm{O}$ site.

Those results are extremely surprising since the general expectation has been that $\mathrm{V}=\mathrm{O}$ is responsible for the high propane activity of the M1 phase.[11, 29]

\subsubsection{Activating the propane $\mathrm{CH}$ bond with $2 \mathrm{~V}$}

Next we considered four $2 \mathrm{~V}$ cases, in which one vanadium occupies S2 while the other occupies another site. Here S4 and S7 are coupled through $\mathrm{O}$ to the $\mathrm{Te}=\mathrm{O}$ that is activating the $\mathrm{CH}$ bond, while S4' and S7' are coupled to the other $\mathrm{Te}=\mathrm{O}$. We find that (energies in $\mathrm{kcal} / \mathrm{mol}$ )

- 2V-a (V@S2,S1): Te=O Do-H $=66.6 \rightarrow \mathrm{E}_{\mathrm{a}, \min }=34.1 ; \mathrm{S} 1$ too far from $\mathrm{Te}=\mathrm{O}$ at $\mathrm{S} 12$ for ROA.

- 2V-b (V@S2,S3): $\mathrm{Te}=\mathrm{O} \mathrm{D}_{\mathrm{o}-\mathrm{H}}=66.6 \rightarrow \mathrm{E}_{\mathrm{a} \text {,min }}=34.1$; $\mathrm{S} 3$ also too far from $\mathrm{Te}=\mathrm{O}$ at $\mathrm{S} 12$ for ROA.

- 2V-c (V@S2,S4): $\mathrm{Te}=\mathrm{O} \mathrm{D}_{\mathrm{O}-\mathrm{H}}=71.1 \rightarrow \mathrm{E}_{\mathrm{a}, \min }=29.6 ; \mathrm{V}$ at $\mathrm{S} 4$ enhances ROA by 4.5.

- 2V-d (V@S2,S7'): Te=O Do-H $=74.5 \rightarrow \mathrm{E}_{\mathrm{a}, \mathrm{min}}=26.2 \mathrm{~V}$ at S7’ enhances ROA by 7.9. 
We also examined 2V cases without vanadium at S2 (not shown in Figure 3). Here we find (energies in $\mathrm{kcal} / \mathrm{mol}$ ) that

- V@S4, S7’: $\mathrm{E}_{\mathrm{a}, \mathrm{min}}=38.6$; ROA decreased.

- V@S7, S7’: $\mathrm{E}_{\mathrm{a}, \mathrm{min}}=32.9$; a slight increase by 1.3.

This indicates that to achieve the most reactive $\mathrm{Te}=\mathrm{O}$ moiety, it is essential to ensure that $\mathrm{S} 2$ is occupied by vanadium.

\subsubsection{Activating the propane $\mathrm{CH}$ bond with $3 \mathrm{~V}$}

Based on the $2 \mathrm{~V}$ results, we consider additional $\mathrm{V}$ only at S4 and S7 sites adjacent to the $\mathrm{Te}=\mathrm{O}$ site. Here we find that

- $\quad 3 V-a(V @ S 2, S 4, S 7): T e=O D_{\mathrm{O}-\mathrm{H}}=72.9 \rightarrow \mathrm{E}_{\mathrm{a}, \mathrm{min}}=27.8$; S7 enhances ROA from S4 by 1.8.

- 3V-b (V@S2,S4,S7’): Te=O D 4.0.

- 3V-c (V@S2,S4,S4'): Te=O D 1.8 .

- 3V-d (V@S2,S7,S7’): Te=O D 0.9 .

Interestingly, $\mathrm{V}$ at S7' seems more important than $\mathrm{V}$ at S7, which is closer to the activating $\mathrm{Te}=\mathrm{O}$ bond. This may be because the substitution of Mo for $\mathrm{V}$ at various sites may change the oxidation states of the other $\mathrm{V}$ (particularly the $\mathrm{V}$ at S2 which for the $1 \mathrm{~V}$ case was in the +4 oxidation state). Summarizing the $3 \mathrm{~V}$ case, the biggest ROA is obtained with V at S2 and S7' plus either S4 or S7.

\subsubsection{Activating the propane $\mathrm{CH}$ bond with $4 \mathrm{~V}$ and $5 \mathrm{~V}$}

Based on the results for $3 \mathrm{~V}$, we considered two $4 \mathrm{~V}$ cases and one $5 \mathrm{~V}$ case. The results are (energies in $\mathrm{kcal} / \mathrm{mol}$ )

-4V-a (V@S2, S4, S4',S7): Te=O D

-4V-b (V@S2, S4, S7, S7’): Te=O D

- 5V (V@S2, S4, S4’, S7, S7’ ): Te=O D

- 4V (V@S4, S4', S7, S7’, not shown in Figure 3): Te=O D

Thus the $5 \mathrm{~V}$ case leads to a very favorable $\mathrm{E}_{\mathrm{a} \text {,min }}=22.7 \mathrm{kcal} / \mathrm{mol}$, making it a most active site. Note that replacing vanadium at S2 with molybdenum, leads to $E_{a, \min }=29.4 \mathrm{kcal} / \mathrm{mol}$, an increase by $6.7 \mathrm{kcal} / \mathrm{mol}$, indicating that occupying $\mathbf{S} 2$ with $\mathbf{V}$ is crucial to maximizing the rate of $\mathbf{C}-\mathbf{H}$ activation by $\mathbf{T e}=0$.

Generally, surrounding $\mathrm{Te}=\mathrm{O}$ by more $\mathrm{V}$ neighbors coupled via an $\mathrm{O}$ with the Te increases its reactivity. This discovery is consistent with experimental results, showing that the rate of propane consumption is correlated with the surface concentration of vanadium in the M1 phase.[30] , Experiments by Ueda and co-workers showed that the rate of propane oxidation catalyzed by Mo$\mathrm{V}-\mathrm{O}$ is almost the same as that catalyzed by Mo-V-Nb-Te-O, suggesting that initial C-H cleavage may not involve $\mathrm{Te}=\mathrm{O}$, which seems to conflict with our DFT results.[31] However, it is likely 
that in the Mo-V-O system, propane C-H activation is not through the ROA pathway. This would lead to a higher activation barrier. Further investigation of the Mo-V-O system is needed to verify this speculation.

Summarizing, we found that as the number of vanadium near the $\mathrm{O}=\mathrm{Te}$ increases from one to five, the $\mathrm{D}_{\mathrm{O}-\mathrm{H}}$ of $\mathrm{O}=\mathrm{Te}$ increases from $66.4 \mathrm{kcal} / \mathrm{mol}$ for $1 \mathrm{~V}$, up to $74.5 \mathrm{kcal} / \mathrm{mol}$ for $2 \mathrm{~V}$, up to 75.2 $\mathrm{kcal} / \mathrm{mol}$ for $3 \mathrm{~V}$, up to $77.1 \mathrm{kcal} / \mathrm{mol}$ for $4 \mathrm{~V}$, and finally to $78.0 \mathrm{kcal} / \mathrm{mol}$ for $5 \mathrm{~V}$ (Figure 3).[5] Figure 4 shows how the $\mathrm{O}=$ Te becomes more reactive as more of its Mo neighbors are replaced by V.

Figure 3. Calculated $\mathrm{D}_{\mathrm{O}-\mathrm{H}}\left(\mathrm{E}_{\mathrm{a}, \mathrm{min}}\right)$ for $\mathrm{Te}=\mathrm{O}$ on the $\mathrm{M} 1$ phase of Mo-V-Nb-Te-O [001] surface. Unit is in $\mathrm{kcal} / \mathrm{mol}$. Pink, brown, green, and blue polyhedrons represent those with centers being occupied by $\mathrm{Mo}=\mathrm{O}, \mathrm{Te}=\mathrm{O}, \mathrm{Nb}=\mathrm{O}$, and $\mathrm{V}=\mathrm{O}$, respectively.
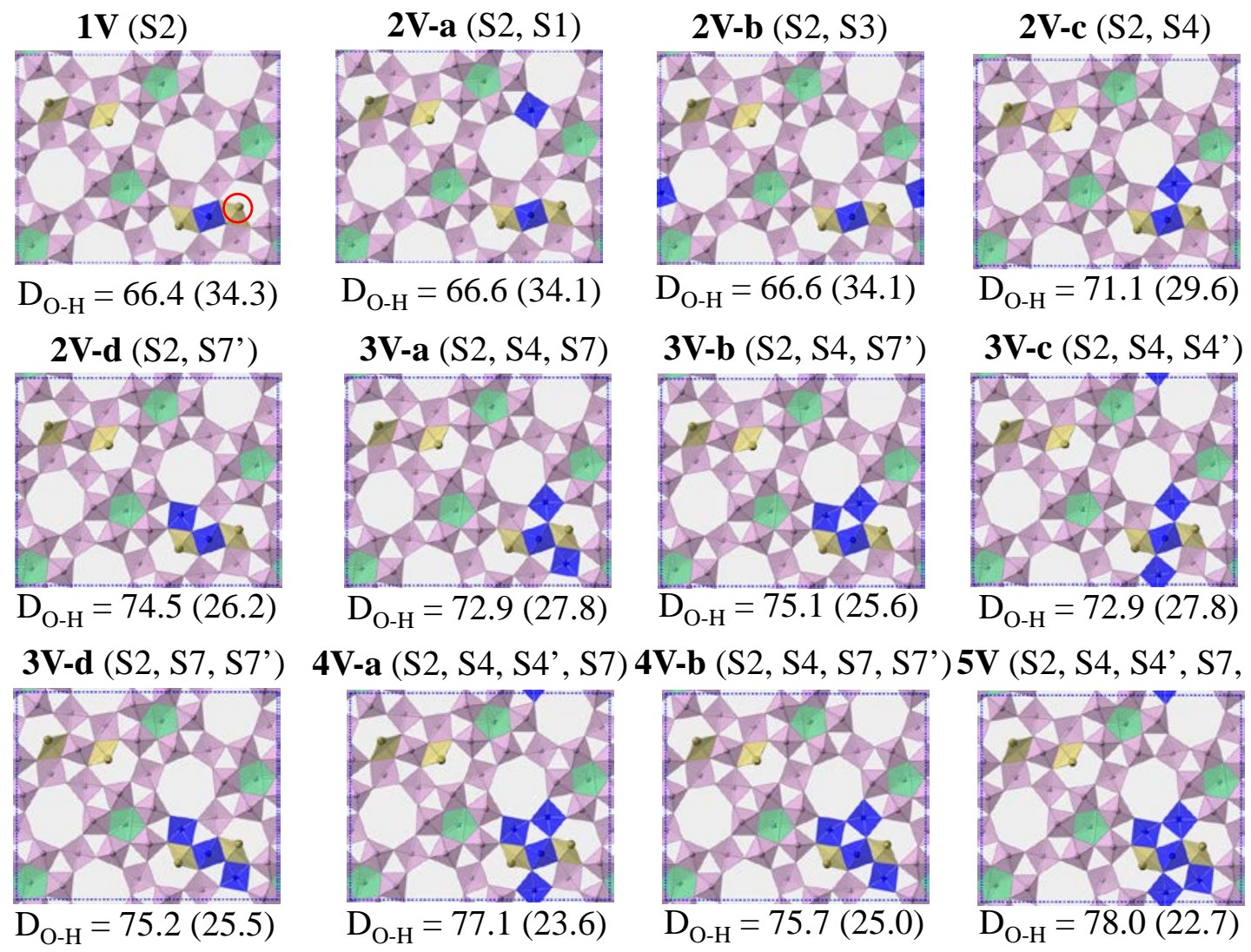

Figure 4. Dependence of the maximum $\mathrm{D}_{\mathrm{O}-\mathrm{H}}$ bond to the $\mathrm{Te}=\mathrm{O}$ on the number of $\mathrm{V}$ in the neighboring sites (S2, S4, S4', S7, and S7') 


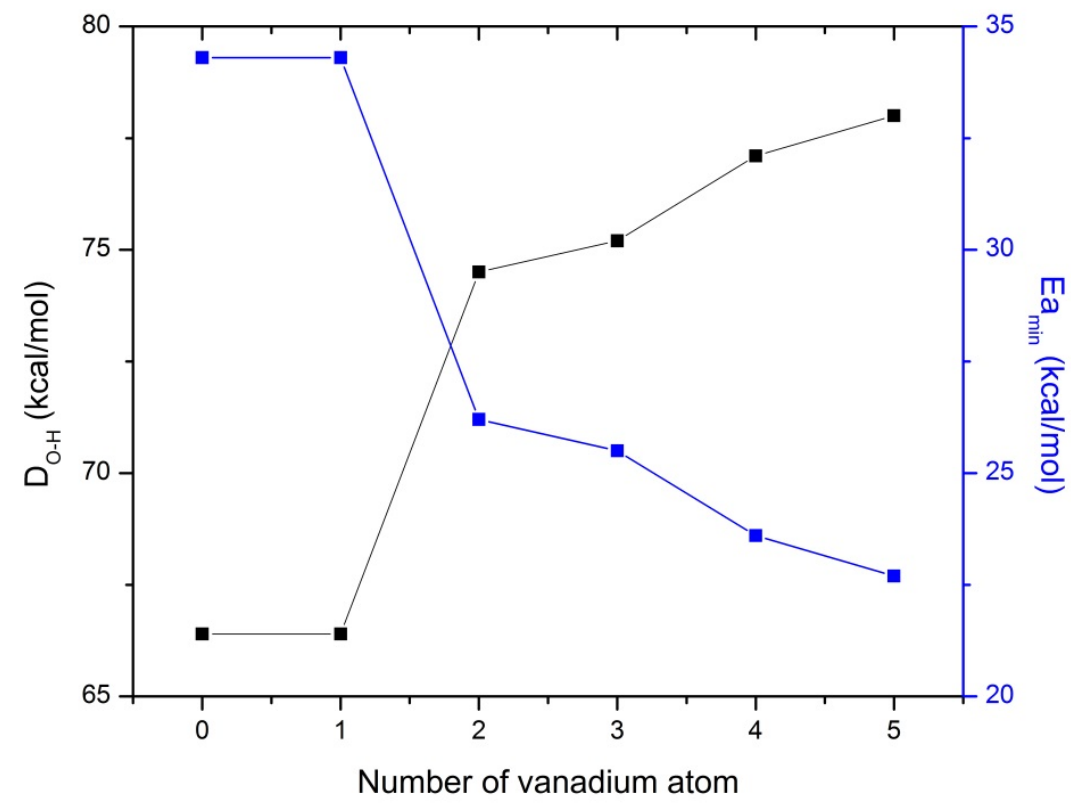

\subsubsection{Site probabilities}

Given the site occupations of with 58\% V at S2, $20 \% \mathrm{~V}$ at S4, and $24 \% \mathrm{~V}$ at S7,[4] the total probability of the various configurations and the $\mathrm{E}_{\mathrm{a}, \mathrm{min}}$ are as follows:

- S2-S7: $13.54 \%$ with $\mathrm{E}_{\mathrm{a}, \mathrm{min}}=26.2 \mathrm{kcal} / \mathrm{mol}$

- S2-S4-S7: $1.69 \%$ with $\mathrm{E}_{\mathrm{a}, \mathrm{min}}=25.6 \mathrm{kcal} / \mathrm{mol}$

- S2-S4-S7’: $1.69 \%$ with $\mathrm{E}_{\mathrm{a} \text {,min }}=25.5 \mathrm{kcal} / \mathrm{mol}$

- S2-S4-S4'-S7: 0.84\% with $\mathrm{E}_{\mathrm{a} \text {, min }}=23.6 \mathrm{kcal} / \mathrm{mol}$

- S2-S4-S7-S7': 1.06\% with $\mathrm{E}_{\mathrm{a}, \min }=25.0 \mathrm{kcal} / \mathrm{mol}$

- S2-S4-S4'-S7-S7: 0.13\% with $\mathrm{E}_{\mathrm{a}, \mathrm{min}}=22.7 \mathrm{kcal} / \mathrm{mol}$

Thus at operational temperatures of $700 \mathrm{~K}$, it is likely that several such sites contribute, leading to complex temperature dependent pathways.

\subsection{Formation of propene}

Above, we considered just propane activation, since this is the rate limiting step. But we must also consider how this activation event leads to the propene product. That M1 does carry out oxidative dehydrogenation (ODH) of propane to propene has been confirmed experimentally to be the first step of propane ammoxidation to acrylonitrile.[32]

The transition state for $\mathrm{CH}$ activation leads directly to formation of the iso-propyl radical which we expect to immediately react with a neighboring oxo bond. Since the oxo bonds on the $\mathrm{S} 4$ and S7 sites point away from the surface, we expect that the iso-propyl is trapped immediately by the $\mathrm{V}=\mathrm{O}$ at $\mathrm{S} 2$ to form a $\mathrm{V}-\mathrm{O}-\mathrm{CH}\left(\mathrm{CH}_{3}\right)_{2}$ moiety. This is exothermic by $39.3 \mathrm{kcal} / \mathrm{mol}$, leading to an intermediate more stable than the reactant by $16.6 \mathrm{kcal} / \mathrm{mol}$. We expect this $\mathrm{OCH}\left(\mathrm{CH}_{3}\right)_{2}$ unit 
to rotate about the $\mathrm{V}-\mathrm{O}$ axis, allowing it to be close enough to the other $\mathrm{Te}=\mathrm{O}$ bond, which can extract the $\mathrm{H}$ from one of the terminal $\mathrm{CH}_{3}$ to form a Te-OH bond while releasing propene. Assuming that this $\mathrm{Te}=\mathrm{O}$ bond is also $78.0 \mathrm{kcal} / \mathrm{mol}$ leads to a reactive step that is 6.0 endothermic but strongly favored by the increased entropy due to release of the propene. This final step leads to an energy $10.6 \mathrm{kcal} / \mathrm{mol}$ more stable than the reactant. In this description both H's must go to $\mathrm{Te}=\mathrm{O}$ sites. Since the occupation of S12 with Te is 71\%, the probability of having Te at both S12 sits is $50 \%$. This reaction mechanism is shown in Figure 5.

Figure 5. QM energy surface for oxidative dehydrogenation of propane to propene using the 5V configuration.

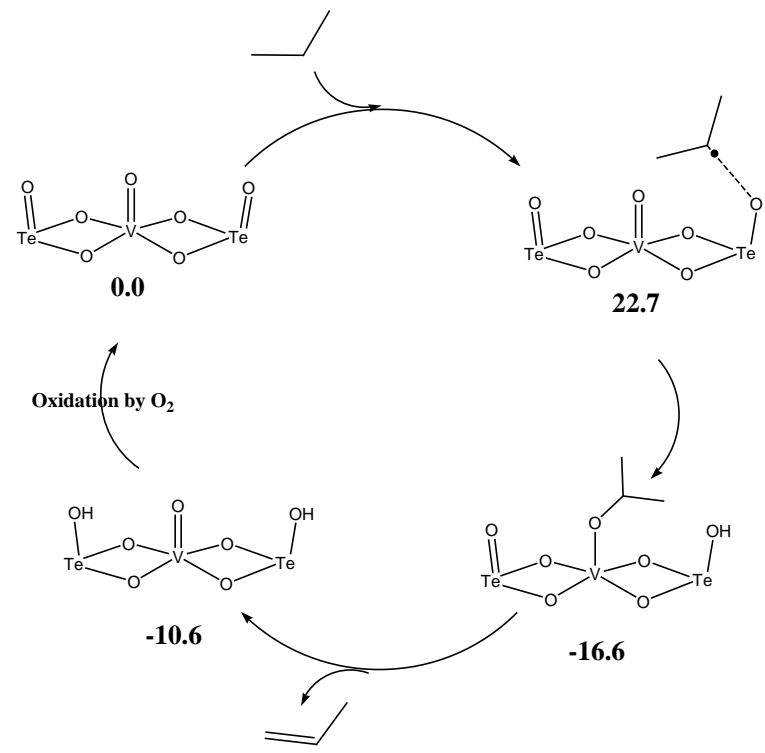

This mechanism provides two sources of reduced selectivity. For the $41 \%$ of the S12-S2-S12 sites that have one but not two $\mathrm{Te}=\mathrm{O}$, the $\mathrm{V}-\mathrm{O}-\mathrm{CH}\left(\mathrm{CH}_{3}\right)_{2}$ might decompose or react with $\mathrm{O}_{2}$ to form other products, including $\mathrm{CO}$ and $\mathrm{CO}_{2}$. Also the iso-propyl radical might not be trapped by the $\mathrm{V}=\mathrm{O}$ or $\mathrm{Mo}=\mathrm{O}$ at the $\mathrm{S} 2$ site, leading to reactions at other sites or with $\mathrm{O}_{2}$ to yield other products including $\mathrm{CO}$ and $\mathrm{CO}_{2}$.

\subsection{Suggestions on improving the selectivity of the M1 phase}

The current Mo-V-Nb-Te-O mixed metal oxide catalysts involves a distribution of grains or phases for which the optimum is to have $60 \% \mathrm{M} 1$ phase and $40 \% \mathrm{M} 2$ phase.[4, 11] It is believed that the highest selectivity is achieved when propene produced by ODH of propane on M1 migrates quickly to M2 for subsequent functionalization to acrylonitrile.[10, 29] This migration process is important, because M1 which leads to an $\mathrm{E}_{\mathrm{a}, \mathrm{min}}=22.7 \mathrm{kcal} / \mathrm{mol}$ for activating the strong propane $\mathrm{C}-\mathrm{H}$ bonds $(100.7 \mathrm{kcal} / \mathrm{mol})$, would have $\mathrm{E}_{\mathrm{a} \text {,min }}=7.3 \mathrm{kcal} / \mathrm{mol}$ for activating the $86.3 \mathrm{kcal} / \mathrm{mol} \mathrm{CH}$ bond of propene to form allyl radical which may lead to other decomposition products including $\mathrm{CO}$ and $\mathrm{CO}_{2}$.[29] Indeed, the selectivity increases for catalysts having smaller grains, which would likely reduce the time for propene to transfer from M1 to M2.[10, 29] However, the difficulty for the synthesis to adjust the spacing and oxidation levels of such two-phase regions to achieve the optimum selectivity.

Our calculations suggest a strategy for building a single phase catalyst that would be selective for ammoxidation or oxidation. We found above that $\mathrm{MoNbTeO}_{\mathrm{x}}$ with no $\mathrm{V}$ leads to $\mathrm{Te}=\mathrm{O}$ sites 
with $\mathrm{D}_{\mathrm{O}-\mathrm{H}}=66.4 \mathrm{kcal} / \mathrm{mol}$, resulting in $\mathrm{E}_{\mathrm{a}, \mathrm{min}}=34.3 \mathrm{kcal} / \mathrm{mol}$ for activating propane, too small to contribute. But this site leads to $\mathrm{E}_{\mathrm{a}, \mathrm{min}}=34.3-14.3=20.0 \mathrm{kcal} / \mathrm{mol}$ for activating propene to allyl. We have described elsewhere[33, 34] the mechanism by which trapping allyl onto $\mathrm{Mo}=\mathrm{NH}$ and $\mathrm{Mo}=\mathrm{O}$ sites leads to formation of acrylonitrile or acrolein. Thus a catalyst with a single $\mathrm{Te}_{2} \mathrm{~V}_{5} \mathrm{O}_{\mathrm{x}}$ site in a matrix of $\mathrm{MoNbTeO}_{\mathrm{x}}$ would activate propane to propene with an $\mathrm{E}_{\mathrm{a} \text {,min }}$ of $22.7 \mathrm{kcal} / \mathrm{mol}$, leaving this site deactivated until it is eventually re-oxidized. Thus there would be no sites to over oxidize the propene. Instead, the propene would be activated by Te sites with no $\mathrm{V}$ neighbors, leading to allyl that would be trapped by the nearby $\mathrm{Mo}=\mathrm{N}$ or $\mathrm{Mo}=\mathrm{O}$ sites to form $\mathrm{AN}$ or acrolein. Thus this catalyst with an isolated $\mathrm{Te}_{2} \mathrm{~V}_{5} \mathrm{O}_{\mathrm{x}}$ site should lead to increased selectivity for production of $\mathrm{AN}$ or acrolein, probably better than for the $\mathrm{BiMoO}_{\mathrm{x}} \mathrm{MMO}$ catalysts (since the allyl is already formed). There would be an optimum concentration of such sites to maximize both activity and selectivity. As a single phase material with a fixed concentration of such active sites, there should be less variability in the product distributions, which could be optimized.

Of course this raises the issue of how to synthesize such a single phase system. We suggest that this be done by first forming $\mathrm{MoNbTeO}_{\mathrm{x}}$ following all the normal procedures of drying, calcining, etc. This might be annealed by reacting with propene under reaction conditions with $\mathrm{NH}_{3}$ and $\mathrm{O}_{2}$. Then we could impregnate the surfaces of this material with $\mathrm{Te}_{2} \mathrm{~V}_{5} \mathrm{O}_{\mathrm{x}}$ or $\mathrm{V}_{2} \mathrm{O}_{5}$ nanoparticles very dilute on the surface of the catalyst to form the VTe rich regions for propane activation. This structure is shown schematically in Scheme 2. Experiments as a function of the amounts of the $\mathrm{V}$ rich additive could optimize the new single phase catalyst for selectivity, activity, and conversion

\subsection{Site isolation}

One of the fundamental principles governing design of heterogeneous catalysts for selective oxidation is “active site isolation" proposed by Grasselli and co-workers.[35] This states that in order to achieve high product selectivity, reactive centers should be highly separated by inert regions to avoid over-oxidation.

For the M1 phase, Grasselli identified the region involving one S2, two S12, two S4, and two S7 as the likely active region, which would be isolated from the other regions by the surrounding Nb sites.[11, 36, 37] Our QM calculations independently confirm that this is the active region for propane activation. In addition, it is likely that if the propene product would stay within this region, it would selectively transform propene to AN. The reason is that the S12-S2-S12 in this active region is already deactivated so that the nearby sites would be likely to activate propene to allyl with a barrier of $\sim 20 \mathrm{kcal} / \mathrm{mol}$, which would trap on an $\mathrm{Mo}=\mathrm{NH}$ or $\mathrm{Mo}=\mathrm{O}$ to form $\mathrm{AN}$ or acrolein selectively. In this case there may be some loss of selectivity because some S12 sites are not fully occupied with Te so that the propyl radial is not cleanly transformed to propene. Also some of the nearby sites may have V at S4 or S7 sites leading to too low a barrier for propene activation that might lead to other products to decrease selectively to AN.

Our suggestion above for synthesizing a single phase $\mathrm{MoNbTeO}_{\mathrm{x}}$ catalyst that is functionalized by a small concentration of $\mathrm{Te}_{2} \mathrm{~V}_{5} \mathrm{O}_{\mathrm{x}}$ nanoparticles near the surface, can be viewed a special case of site isolation (Scheme 2).[5] 


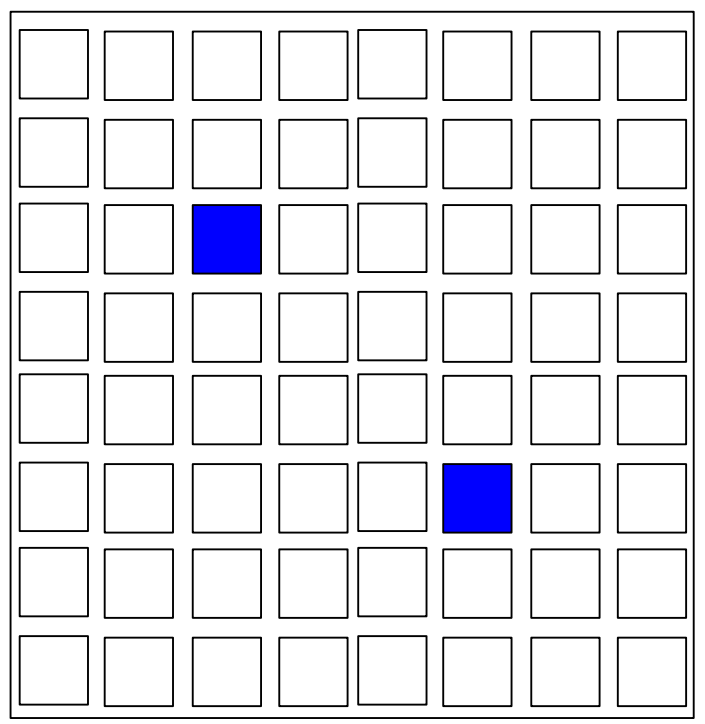

Scheme 2. Design of single phase catalyst for highly selective ammoxidation. The matrix is $\mathrm{MoNbTeO}_{\mathrm{x}}$ embedded at the surface with $\mathrm{Te}_{2} \mathrm{~V}_{5} \mathrm{O}_{\mathrm{x}}$ nanoclusters (blue squares) that are highly dispersed so that the propene formed at the $\mathrm{Te}_{3} \mathrm{~V}_{5} \mathrm{O}_{\mathrm{x}}$ site is converted to AN before encountering an another active $\mathrm{T}_{2} \mathrm{~V}_{5} \mathrm{O}_{\mathrm{x}}$ cluster.

\subsection{Oxidative dehydrogenation of ethane}

The $\mathrm{Te}_{2} \mathrm{~V}_{5} \mathrm{O}_{\mathrm{x}}$ site that converts propane to propene would also convert ethane $\left(\mathrm{D}_{\mathrm{C}-\mathrm{H}}=103.0\right.$ $\mathrm{kcal} / \mathrm{mol}$ ) to ethene with similar energetics. Since the $\mathrm{CH}$ bond of ethene is $\mathrm{D}_{\mathrm{C}-\mathrm{H}}=115.6 \mathrm{kcal} / \mathrm{mol}$, we would expect the barrier for the ethene to be activated by another $\mathrm{Te}_{2} \mathrm{~V}_{2} \mathrm{O}_{\mathrm{x}}$ site to have $\mathrm{E}_{\mathrm{a} \text {,min }} \sim$ $40 \mathrm{kcal} / \mathrm{mol}$ so that the M1 phase should be highly selective for $\mathrm{ODH}$ of ethane. Indeed the reaction could be run at very high conversion with little subsequent oxidation of the ethylene.

The advent of petroleum fracking has led to gases containing significant concentrations of both ethane and propane along with methane.[38] Thus it would be useful to have an ODH catalyst that could work on both propane and ethane. Here we suggest a variation on the catalyst proposed in Scheme 2 in which the matrix is now $\mathrm{MoNbO}_{\mathrm{x}}$ with no Te, so that it would not activate propene. Here we still want the $\mathrm{Te}_{2} \mathrm{~V}_{5} \mathrm{Ox}$ sites in Scheme 2 to be sufficiently isolated that the propene would not encounter a remote active $\mathrm{Te}_{2} \mathrm{~V}_{5} \mathrm{O}_{\mathrm{x}}$ site. This concertation of $\mathrm{Te}_{2} \mathrm{~V}_{5} \mathrm{O}_{\mathrm{x}}$ site would determine the optimum combination of activity, conversion, and selectivity.

\subsection{Design of organometallic complexes that activate alkane $\mathrm{C}-\mathrm{H}$ bond through the ROA mechanism}

\subsection{Relation of ROA to common mechanisms for $\mathrm{CH}$ activation in organometallics}

This ROA mechanism so important for catalysis by VPO and Mo-V-Nb-Te-O MMO systems, may also be the fundamental mechanism for many other heterogeneous catalysts, (including the multimetal BiMoOx propene ammoxidation), where it is very common to have a column 15 or 16 elements such as Se or Te or As, Sb, or Bi combined with transition metals such as V or Mo. However our search of the literature could find no organometallic catalysts that might to involve this ROA mechanism for alkane C-H activation.[6] In organometallics, all the known C-H activation mechanisms can be grouped into two categories. 
- Metal activated. A metal-carbon bond is formed in the reaction by binding directly with the activated alkyl fragment (Scheme 3(a)).[39, 40] Examples include (1) oxidative addition, (2) electrophilic substitution, (3) $\sigma$-bond metathesis, and (4) 1,2-addition.

- Metal-oxo activated. Here $\mathrm{C}-\mathrm{H}$ cleavage is through hydrogen abstraction by a metal-oxo $(\mathrm{M}=\mathrm{O})$ motif to form $\mathrm{M}-\mathrm{OH}$ plus a radical, which reduces the metal by one electron, but the metal is not involved directly (Scheme 3(b)). [40] Then the radical reacts with the M-OH forms an $\mathrm{C}-\mathrm{OH}$ bond to form an alcohol product (the rebound process).[41]

(a)

(1)

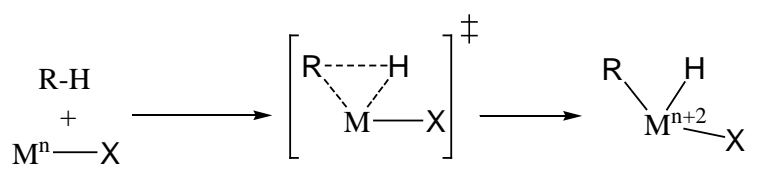

(2)

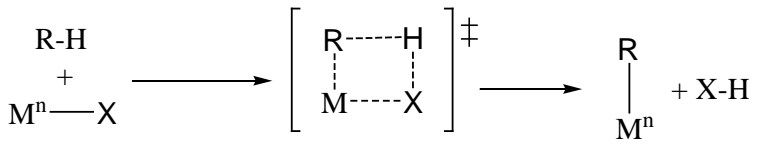

(3)

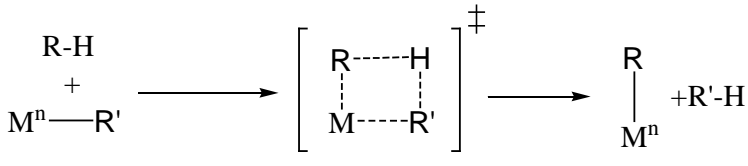

(4)

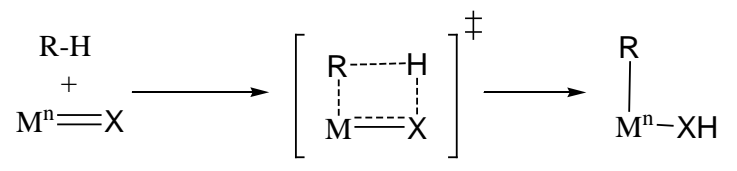

(b)

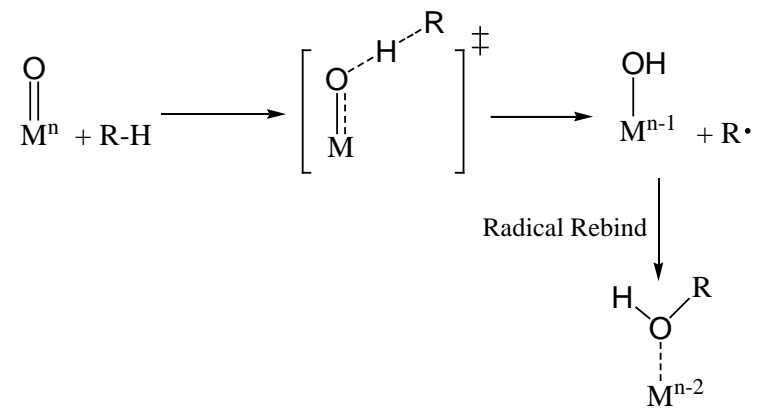

Scheme 3. Mechanisms for C-H cleavage by organometallic catalysts

The ROA mechanism is a unique new 3rd mechanism for $\mathrm{CH}$ activation that provides at least two potential advantages over the two previously known mechanisms.

- ROA protects the precious metal (Pt, Ir, Rh, etc.) from being consumed during the reaction, since there is no direct contact between metal and the reactants.

- The oxo activating group (proton acceptor) and the metal (electron acceptor) are separated from each other by two intervening atoms (-PO-), allowing them to be optimized more independently than in metal-oxo systems. This provides additional degrees of freedom to tune D $\mathrm{O}-\mathrm{H}$.

Since we could not find any examples in the organometallic literature of a $\mathrm{P}=\mathrm{O}$ separated from the transition metal by a bridging $\mathrm{O}$ as in our heterogeneous catalyst, we focus on organometallics in 
which the metal binds direction to the $\mathrm{P}=\mathrm{O}$. Several such an organometallic structures have been synthesized recently,[42-49] but we find that none leads to a particularly strong bond of $\mathrm{H}$ to the $\mathrm{P}=\mathrm{O}$. For such a motif, after hydrogen binds with $\mathrm{O}=\mathrm{P}, \mathrm{P}-\mathrm{M} \sigma$-bond becomes a donor-acceptor bond and metal is reduced by one electron (Scheme 4).

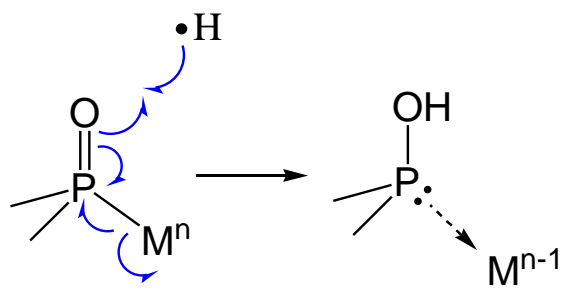

Scheme 4. Valence bond description for the reduction-coupled oxo activation (ROA) principle applied to organometallics with direct P-M bonding

\subsection{Proposed organometallics that would exhibit the ROA mechanism}

We investigated the influence of the metallic center and organic ligand on $\mathrm{D}_{\mathrm{O}-\mathrm{H}}$ to identify the organometallic complexes that can activate alkane $\mathrm{C}-\mathrm{H}$ bonds readily through the ROA principle. To study the effect of the metal center we chose:

- Three group $\mathrm{V}$ metal dichloride complexes with a tri-anionic pincer-type phosphinito ligand (1-V, -Nb, -Ta, Scheme 5). Here we calculated $\mathrm{D}_{\mathrm{O}-\mathrm{H}}=85.6$ for $\mathbf{1 - V}, 66.0$ for $\mathbf{1 - N b}$, and 59.3 $\mathrm{kcal} / \mathrm{mol}$ for 1-Ta.[6]

- Three group $\mathrm{X}$ metal mono chloride complexes with a mono-anionic pincer-type phosphinito

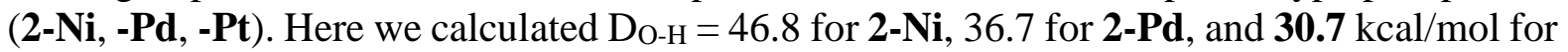
2-Pt.[6]

These results suggest that

(1) the group $\mathrm{V}$ metals are quite promising for the activating strong $\mathrm{C}-\mathrm{H}$ bonds, and

(2) the first-row transition metals are better than second-row, and third-row for increasing $\mathrm{D}_{\mathrm{O}-\mathrm{H}}$.

Based on these results we carried studies on two additional ligands,

- 3-V $\left[\mathrm{NP}(\mathrm{O}) \mathrm{N}^{-3}\right.$ and

- 4-V $[\mathrm{SP}(\mathrm{O}) \mathrm{S}]^{-3}$.

We found $\mathrm{D}_{\mathrm{O}-\mathrm{H}}=80.6 \mathrm{kcal} / \mathrm{mol}$ for $\mathbf{3 - V}$, which is $5.0 \mathrm{kcal} / \mathrm{mol}$ smaller than that of $\mathbf{2 - V}$, whereas $\mathrm{D}_{\mathrm{O}-\mathrm{H}}=89.7 \mathrm{kcal} / \mathrm{mol}$ for $\mathbf{4 - V}$, which is $4.1 \mathrm{kcal} / \mathrm{mol}$ larger than that of $\mathbf{2 - V}$. Using the most reactive 4-V complex to cleave $n$-butane methylene $\mathrm{C}-\mathrm{H}$ bonds gives an energy barrier of only 20.4 $\mathrm{kcal} / \mathrm{mol}$, demonstrating its high reactivity for alkane C-H activation.[6] 


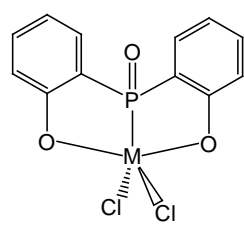

1-V, -Nb, -Ta 85.6, 66.0, 59.3

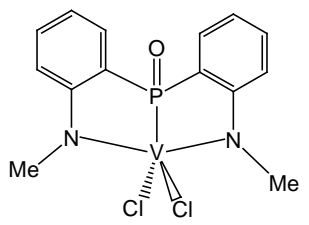

3-V

80.6

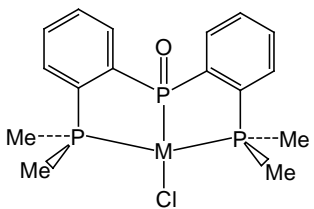

2-Ni, -Pd, -Pt

46.8, 36.7, 30.7

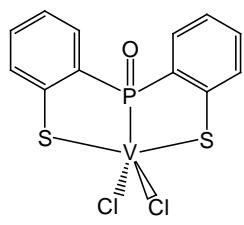

4-V

89.7

Scheme 5. Molecules for evaluating the C-H activation through the organometallic ROA mechanism.

\section{Summary and Conclusions}

We applied quantum mechanics to study two important heterogeneous catalysts, vanadium phosphorus oxide and the M1 phase of Mo-V-Nb-Te-O mixed metal oxide, both of which use alkane as feedstocks. For the vanadium phosphorus oxide system, we discovered that $n$-butane $C$ $\mathrm{H}$ bonds are activated by surface $\mathrm{O}=\mathrm{P}$ not by $\mathrm{O}=\mathrm{V}$. The reason that $\mathrm{O}=\mathrm{P}$ can cleave such a strong $\mathrm{C}-\mathrm{H}$ bond is because it is coupled through an $\mathrm{O}$ to a $\mathrm{V}^{+5}$ transition metal that is easy to reduce. This is the Reduction-Coupled Oxo Activation (ROA) mechanism.

Then our QM study indicates that this ROA mechanism is responsible for propane $\mathrm{C}-\mathrm{H}$ cleavage on the surface of the M1 phase of the Mo-V-Nb-Te-O propane ammoxidation catalyst. In contrast to the VPO system, here it is $\mathrm{O}=$ Te that is used to cleave the propane $\mathrm{C}-\mathrm{H}$ bond with the proton going to the $\mathrm{Te}=\mathrm{O}$ to form $\mathrm{Te}-\mathrm{OH}$, while the electron goes to the nearby $\mathrm{Mo}=\mathrm{O}$ or $\mathrm{V}=\mathrm{O}$ sites. Most important is that we found the reactivity of $\mathrm{O}=$ Te to increase significantly as additional sites bridging through an $\mathrm{O}$ to the Te have the Mo replaced by $\mathrm{V}$. With this understanding of the mechanism, we proposed a new strategy to synthesize a single phase with active site isolation aimed at improving the selectivity by separating vanadium-rich $\mathrm{O}=$ Te with intervening regions containing only vanadium poor Mo-Nb-Te-O sites sufficiently large that the propene is converted to AN before encountering a second $\mathrm{Te}_{2} \mathrm{~V}_{5} \mathrm{O}_{\mathrm{x}}$ active site. We also proposed a modified single phase catalyst containing isolated $\mathrm{Te}_{2} \mathrm{~V}_{5} \mathrm{O}_{\mathrm{x}}$ active site in a $\mathrm{MoNbO}_{\mathrm{x}}$ matrix containing no $\mathrm{V}$ or Te that should be very selective and active for simultaneous conversion of ethane and propane to ethene and propene.

Finally, we applied this ROA principle to design homogeneous catalysts for alkane $\mathrm{C}-\mathrm{H}$ activation. The vanadium complexes that we proposed can activate $n$-butane $\mathrm{C}-\mathrm{H}$ bonds with a kinetic barrier of only $20.4 \mathrm{kcal} / \mathrm{mol}$, suggesting its high reactivity toward C-H activation.

\section{Acknowledgements}

This work was supported by the National Science Foundation (CHE-1214158, Carol Bessel and Carlos Murillo). We thank Robert Grasselli, Doug Buttrey, Robert Nielsen, and Ross Fu for helpful discussions. 


\section{References}

[1] M.J. Cheng, R.J. Nielsen, J. Tahir-Kheli, W.A. Goddard, The magnetic and electronic structure of vanadyl pyrophosphate from density functional theory, Phys Chem Chem Phys, 13 (2011) 9831-9838.

[2] M.J. Cheng, W.A. Goddard, R. Fu, The Reduction-Coupled Oxo Activation (ROA) Mechanism Responsible for the Catalytic Selective Activation and Functionalization of n-Butane to Maleic Anhydride by Vanadium Phosphate Oxide, Top Catal, 57 (2014) 1171-1187.

[3] M.J. Cheng, W.A. Goddard, The Critical Role of Phosphate in Vanadium Phosphate Oxide for the Catalytic Activation and Functionalization of n-Butane to Maleic Anhydride, J Am Chem Soc, 135 (2013) 4600-4603.

[4] X. Li, D.J. Buttrey, D.A. Blom, T. Vogt, Improvement of the Structural Model for the M1 Phase Mo-V-Nb-Te-O Propane (Amm)oxidation Catalyst, Top Catal., 54 (2011) 614-626.

[5] M.J. Cheng, W.A. Goddard, In Silico Design of Highly Selective Mo-V-Te-Nb-O Mixed Metal Oxide Catalysts for Ammoxidation and Oxidative Dehydrogenation of Propane and Ethane, J Am Chem Soc, 137 (2015) 13224-13227.

[6] M.J. Cheng, R. Fu, W.A. Goddard, Design and validation of non-metal oxo complexes for CH activation, Chem. Commun., 50 (2014) 1748-1750.

[7] J.P. Perdew, K. Burke, M. Ernzerhof, Generalized gradient approximation made simple, Phys. Rev. Lett., 77 (1996) 3865-3868.

[8] K.F. Garrity, J.W. Bennett, K.M. Rabe, D. Vanderbilt, Pseudopotentials for high-throughput DFT calculations, Comput. Mater. Sci., 81 (2014) 446-452.

[9] P. Giannozzi, S. Baroni, N. Bonini, M. Calandra, R. Car, C. Cavazzoni, D. Ceresoli, G.L. Chiarotti, M. Cococcioni, I. Dabo, A. Dal Corso, S. de Gironcoli, S. Fabris, G. Fratesi, R. Gebauer, U. Gerstmann, C. Gougoussis, A. Kokalj, M. Lazzeri, L. Martin-Samos, N. Marzari, F. Mauri, R. Mazzarello, S. Paolini, A. Pasquarello, L. Paulatto, C. Sbraccia, S. Scandolo, G. Sclauzero, A.P. Seitsonen, A. Smogunov, P. Umari, R.M. Wentzcovitch, QUANTUM ESPRESSO: a modular and open-source software project for quantum simulations of materials, J. Phys. Condens. Matter, 21 (2009).

[10] J. Holmberg, R.K. Grasselli, A. Andersson, Catalytic behaviour of M1, M2, and M1/M2 physical mixtures of the Mo-V-Nb-Te-oxide system in propane and propene ammoxidation, Appl. Catal., A: Gen., 270 (2004) 121-134.

[11] R.K. Grasselli, J.D. Burrington, D.J. Buttrey, P. DeSanto, C.G. Lugmair, A.F. Volpe, T. Weingand, Multifunctionality of active centers in (amm)oxidation catalysts: from Bi-Mo-O-x to Mo-V-Nb-(Te, Sb)-O-x, Top Catal, 23 (2003) 5-22.

[12] G. Centi, F. Trifiro, J.R. Ebner, V.M. Franchetti, Mechanistic Aspects of Maleic-Anhydride Synthesis from C4-Hydrocarbons over Phosphorus Vanadium-Oxide, Chem. Rev., 88 (1988) 5580 .

[13] T. Saito, T. Terashima, M. Azuma, M. Takano, T. Goto, H. Ohta, W. Utsumi, P. Bordet, D.C. Johnston, Single crystal growth of the high pressure phase of (VO)(2)P2O7 at $3 \mathrm{GPa}$, J. Solid State Chem., 153 (2000) 124-131. 
[14] G. Busca, G. Centi, F. Trifiro, V. Lorenzelli, Surface-Acidity of Vanadyl Pyrophosphate, Active Phase in Normal-Butane Selective Oxidation, J Phys Chem-Us, 90 (1986) 1337-1344.

[15] Y. Schuurman, J.T. Gleaves, Activation of Vanadium Phosphorus Oxide Catalysts for Alkane Oxidation - the Influence of the Oxidation-State on Catalyst Selectivity, Ind Eng Chem Res, 33 (1994) 2935-2941.

[16] J.P. Joly, C. Mehier, K.E. Bere, M. Abon, TPD study of labile oxygen on a (VO)(2)P2O7 catalyst active in n-butane partial oxidation, Appl Catal a-Gen, 169 (1998) 55-63.

[17] P.A. Agaskar, L. Decaul, R.K. Grasselli, A Molecular-Level Mechanism of N-Butane Oxidation to Maleic-Anhydride over Vanadyl Pyrophosphate, Catal Lett, 23 (1994) 339-351.

[18] J.C. Volta, Dynamic processes on vanadium phosphorous oxides for selective alkane oxidation, Catal Today, 32 (1996) 29-36.

[19] G.J. Hutchings, A. Desmartinchomel, R. Olier, J.C. Volta, Role of the Product in the Transformation of a Catalyst to Its Active State, Nature, 368 (1994) 41-45.

[20] G.W. Coulston, S.R. Bare, H. Kung, K. Birkeland, G.K. Bethke, R. Harlow, N. Herron, P.L. Lee, The kinetic significance of V5+ in n-butane oxidation catalyzed by vanadium phosphates, Science, 275 (1997) 191-193.

[21] M. Tachez, F. Theobald, E. Bordes, A Structural Explanation for the Polymorphism of the Alpha-Form of Anhydrous Vanadyl Phosphate, J. Solid State Chem., 40 (1981) 280-283.

[22] B.D. Jordan, C. Calvo, Alpha-V1.08p0.92o5 at 22degreesc, Acta Crystallogr. B, 32 (1976) 2899-2900.

[23] T. Shimoda, T. Okuhara, M. Misono, Preparation of Vanadium-Phosphorus Mixed-Oxide $(\mathrm{P} / \mathrm{V}=1)$ Catalysts and Their Application to Oxidation of Butane to Maleic-Anhydride, B Chem Soc Jpn, 58 (1985) 2163-2171.

[24] G. Koyano, T. Okuhara, M. Misono, Structural changes of surface layer of vanadyl pyrophosphate catalysts by oxidation-reduction and their relationships with selective oxidation of n-butane, J Am Chem Soc, 120 (1998) 767-774.

[25] R.K. Grasselli, Selectivity issues in (amm)oxidation catalysis, Catal Today, 99 (2005) 23-31.

[26] W.A. Goddard, L.C. Liu, J.E. Mueller, S. Pudar, R.J. Nielsen, Structures, Mechanisms, and Kinetics of Ammoxidation and Selective Oxidation of Propane Over the M2 Phase of MoVNbTeO Catalysts, Top Catal, 54 (2011) 659-668.

[27] K. Chenoweth, A.C.T. van Duin, W.A. Goddard, The ReaxFF Monte Carlo Reactive Dynamics Method for Predicting Atomistic Structures of Disordered Ceramics: Application to the Mo3VOx Catalyst, Angew Chem Int Edit, 48 (2009) 7630-7634.

[28] G. Fu, X. Xu, P. Sautet, Vanadium Distribution in Four-Component Mo-V-Te-Nb MixedOxide Catalysts from First Principles: How to Explore the Numerous Configurations?, Angew Chem Int Edit, 51 (2012) 12854-12858.

[29] R.K. Grasselli, D.J. Buttrey, P. DeSanto, J.D. Burrington, C.G. Lugmair, A.F. Volpe, T. Weingand, Active centers in Mo-V-Nb-Te-O-x (amm)oxidation catalysts, Catal Today, 91-2 (2004) 251-258. 
[30] V.V. Guliants, R. Bhandari, H.H. Brongersma, A. Knoester, A.M. Gaffney, S. Han, A study of the surface region of the Mo-V-Te-O catalysts for propane oxidation to acrylic acid, J Phys Chem B, 109 (2005) 10234-10242.

[31] W. Ueda, D. Vitry, T. Katou, Crystalline Mo-V-O based complex oxides as selective oxidation catalysts of propane, Catal Today, 99 (2005) 43-49.

[32] J.M. Oliver, J.M.L. Nieto, P. Botella, Selective oxidation and ammoxidation of propane on a Mo-V-Te-Nb-O mixed metal oxide catalyst: a comparative study, Catal Today, 96 (2004) 241249.

[33] Y.H. Jang, W.A. Goddard, Selective oxidation and ammoxidation of propene on bismuth molybdates, ab initio calculations, Top Catal, 15 (2001) 273-289.

[34] Y.H. Jang, W.A. Goddard, Mechanism of selective oxidation and ammoxidation of propene on bismuth molybdates from DFT calculations on model clusters, J Phys Chem B, 106 (2002) 5997-6013.

[35] R.K. Grasselli, Fundamental principles of selective heterogeneous oxidation atalysis, Top Catal, 21 (2002) 79-88.

[36] R.K. Grasselli, C.G. Lugmair, A.F. Volpe, Towards an Understanding of the Reaction Pathways in Propane Ammoxidation Based on the Distribution of Elements at the Active Centers of the M1 Phase of the MoV(Nb,Ta)TeO System, Top Catal, 54 (2011) 595-604.

[37] R.K. Grasselli, A.F. Volpe, Catalytic Consequences of a Revised Distribution of Key Elements at the Active Centers of the M1 Phase of the MoVNbTeOx System, Top Catal, 57 (2014) 1124-1137.

[38] J.M.L. Nieto, P. Botella, M.I. Vazquez, A. Dejoz, The selective oxidative dehydrogenation of ethane over hydrothermally synthesised MoVTeNb catalysts, Chem. Commun., (2002) 19061907.

[39] B.G. Hashiguchi, S.M. Bischof, M.M. Konnick, R.A. Periana, Designing Catalysts for Functionalization of Unactivated C-H Bonds Based on the CH Activation Reaction, Acc. Chem. Res., 45 (2012) 885-898.

[40] A.E. Shilov, G.B. Shul'pin, Activation of C-H bonds by metal complexes, Chem. Rev., 97 (1997) 2879-2932.

[41] J.T. Groves, Key Elements of the Chemistry of Cytochrome-P-450 - the Oxygen Rebound Mechanism, J. Chem. Educ., 62 (1985) 928-931.

[42] R.C. Bauer, Y. Gloaguen, M. Lutz, J.N.H. Reek, B. de Bruin, J.I. van der Vlugt, Pincer ligands with an all-phosphorus donor set: subtle differences between rhodium and palladium, Dalton T, 40 (2011) 8822-8829.

[43] E.J. Derrah, S. Ladeira, G. Bouhadir, K. Miqueu, D. Bourissou, Original phenyl-P(O) bond cleavage at palladium(0): a combined experimental and computational study, Chem. Commun., 47 (2011) 8611-8613.

[44] E.J. Derrah, C. Martin, S. Ladeira, K. Miqueu, G. Bouhadir, D. Bourissou, Coordination of a diphosphine-phosphine oxide to $\mathrm{Au}, \mathrm{Ag}$ and $\mathrm{Rh}$ : when polyfunctionality rhymes with versatility, Dalton T, 41 (2012) 14274-14280. 
[45] Y. Gloaguen, W. Jacobs, B. de Bruin, M. Lutz, J.I. van der Vlugt, Reactivity of a Mononuclear Iridium(I) Species Bearing a Terminal Phosphido Fragment Embedded in a Triphosphorus Ligand, Inorg. Chem., 52 (2013) 1682-1684.

[46] M. Mazzeo, M. Lamberti, A. Massa, A. Scettri, C. Pellecchia, J.C. Peters, Phosphido Pincer Complexes of Palladium as New Efficient Catalysts for Allylation of Aldehydes, Organometallics, 27 (2008) 5741-5743.

[47] M. Mazzeo, M. Strianese, O. Kuhl, J.C. Peters, Phosphido pincer complexes of platinum: synthesis, structure and reactivity, Dalton T, 40 (2011) 9026-9033.

[48] B.F. Pan, M.W. Bezpalko, B.M. Foxman, C.M. Thomas, Coordination of an N-Heterocyclic Phosphenium Containing Pincer Ligand to a $\mathrm{Co}(\mathrm{CO})(2)$ Fragment Allows Oxidation To Form an Unusual N-Heterocyclic Phosphinito Species, Organometallics, 30 (2011) 5560-5563.

[49] B.F. Pan, M.W. Bezpalko, B.M. Foxman, C.M. Thomas, Heterolytic addition of E-H bonds across Pt-P bonds in Pt N-heterocyclic phosphenium/phosphido complexes, Dalton T, 41 (2012) 9083-9090. 